\title{
Beyond Tocqueville: The Origins of Social Capital in Switzerland
}

\author{
Markus Freitag
}

This paper evaluates the foundations of social capital as measured in terms of social trust in Switzerland. Specifically, the standard view that face-to-face interaction within voluntary associations is the dominant way to create social capital (the so-called Tocqueville model) will be challenged. While providing no support for the thesis that active membership in associations fosters social trust, our results strongly support explanations that point to personal resources, social background variables, psychological determinants, and individual attitudes, which can only be explained effectively by the socialization process within the family and in early adulthood experiences. In fact, based on the Swiss data from the World Values Survey in the mid-1990s, social trust is contingent upon life satisfaction, confidence in political and societal institutions, education, cosmopolitan culture, daily television consumption, and regional provenance.

\section{Introduction}

The idea of social capital currently appears on the agenda of modern social science. Before 1981, only twenty essays referring to social capital had been published without attracting much attention. ${ }^{1}$ In the wake of the work done by Coleman $(1988,1990)$ and Putnam (1993), articles dealing with this theme grew to over 100 between 1991 and 1995, and in the following four years to 1999 more than 1000 contributions had ascribed importance to social capital (Winter, 2000: 17). ${ }^{2}$ Despite this impressive triumphal procession, one of the most controversial issues about social capital remains (Torcal and Montero, 1999: 167): how is it formed? Accordingly, the purpose of this paper is to evaluate the origins of social capital, measured in terms of social trust. The analysis is confined to Switzerland.

This investigation is motivated by three key arguments. First, the present economic, sociological and political science literature interested in economic development, institutional performance, or democratic legitimacy assigns the concept of social capital a key role. Social capital within a community contributes positively to government performance (Cusack, 1999; Putnam, 1993). In addition, a number of studies have shown that the accumulation of social capital enhances economic development through the reduction of transaction costs, for example, the cost of monitoring, contracting, adjudicating, and enforcing formal agreements (Knack and Keefer, 1997; Whiteley, 2000). Besides, the existence and maintenance of social capital is believed to generally reduce problems associated with collective action (Diekmann, 1993; Jordana, 1999; Rothstein, 2000). Finally, some scholars argue that social capital is likely to strengthen political participation (Joye and Laurent, 1997; Kunz and Gabriel, 2000). These findings are startling and ask us to question the foundations of this lubricant for contemporary societies. Secondly, while social capital as a buzzword garners particular attention 
in the social sciences, so far Switzerland has not been a part of this rapidly growing body of work. Hence, this case marks a specific research gap. ${ }^{3}$ The intention of this paper is to apply the insights from other studies that evaluate the foundations of social capital to the Swiss case. For example, recent analyses have been conducted for Britain, France, Germany, Italy, the Netherlands, Spain, and the United States (Newton, 1999a; Torcal and Montero, 1999; Whiteley, 1999). Against this background, it is in our interest to apply the explanations of the sources of social capital in Western democracies to Switzerland. Thirdly, the late Stein Rokkan once called Switzerland a microcosm of Europe due to its cultural, religious, and regional diversity (Linder, 1994: xii). In this vein, Rokkan recommended that anyone wishing to study the dynamics of European politics and society should immerse themselves in the study of Switzerland.

The goal of this research is twofold. First, the paper attempts to fill a gap and evaluates the foundations of social capital measured in terms of social trust in Switzerland. Secondly, the article elaborates and tests competing hypotheses about the origins of social trust. Specifically, we challenge the standard view that face-to-face interaction within voluntary associations is the dominant way to create social trust (the so-called Tocqueville model). Instead, our results strongly support explanations that point to personal resources, social background variables, psychological determinants, and individual attitudes, which can only be explained effectively by the socialization process within the family and in early adulthood experiences. Indeed, the analysis provides no empirical support for the thesis that active membership in various kinds of associations fosters social trust.

Our argument will be presented in a series of steps. First, the concept of social capital and how it is measured is briefly introduced. Based on a discussion of the major hypotheses that can be found in the literature on social capital, we then identify the core independent variables that will be included in the analysis. The following section describes the design of the study and the data analysed. This leads to the specification of multivariate logistic regression models, designed to test alternative explanations, using data from the World Values Survey (see Inglehart et al., 2000). We conclude with a discussion of the major findings.

\section{The Dependent Variable}

The concept of social capital entails several components and is therefore measured in several ways. Putnam (1995b: 664-665), for example, merges a variety of meanings as he defines social capital as 'features of social life, networks, norms, and trust, that enable participants to act together more effectively to pursue shared objectives'. But for all that, much of the scholarly attention given to social capital in recent years has focused on social networks and interpersonal trust as the two main aspects or dimensions of the concept (Brehm and Rahn, 1997; Coleman, 1990; Fukuyama, 2000; Putnam, 1993, 1995a, 1995b, 2000; Newton, 1999b). On the one hand, social connectedness and the civic engagement of individuals such as membership in associations are seen as a crucial component of social capital, because they embody a capability to mobilize a wide range of personal contacts which are decisive in the improvement and effective functioning of one's social and political life. On the other hand, defined as subjective norms of trust, social capital involves attitudes people have about their fellow citizens and therefore unfolds how individuals are affiliated with each other. Although these two dimensions are closely interrelated, there are reasons to keep them apart conceptually. Accordingly, norms and values like social trust are subjective and intangible, thereby referring to a more qualitative dimension. However, social networks are objective and easier to observe, thus these belong to a rather quantitative dimension (Newton, 1997: 577; Paxton, 1999).

In the present context, we follow Whiteley (2000: 450) and define social capital 'as the willingness of citizens to trust others including members of their own family, fellow citizens, and people in general'. Social trust is not just a handy empirical way to measure social capital, which makes the concept amenable to survey investigation. ${ }^{4}$ Indeed, according to Coleman (1990: 306-307) trust is the essential part of social capital. It furthers norms which abdicate egocentric calculations and self interest. Moreover, it strengthens the willingness of individuals to act in the interest of the group or community in order to overcome social dilemmas. According to this view, trust promotes reciprocity and co-operation beyond tit-for-tat schemes 
(Whiteley, 1999, 2000). In fact, trust stimulates a type of generalized reciprocity, where altruistic behaviour and obligations will be repaid at some unspecified time, at some unspecified location, by an unspecified person. Generalized norms of trust and reciprocity involve a leap of faith in which the trustworthiness of those you know can be broadened to include others beyond your personal sphere (Stolle and Rochon, 1999: 197). As a result, trusting individuals create and maintain an environment of trustworthiness which sustains the social fabric (Putnam, 1995a). Clearly, this kind of environment facilitates social interactions that otherwise would not be possible. Thus, psychological research and surveys confirm that social trust constrains immoral behaviour. Trusting individuals are themselves more trustworthy and honest and are less likely to lie, cheat, or steal (Gurtman, 1992; Rotter, 1971, 1980). Last but not least, in a trust-driven surrounding of generalized reciprocity, we are able to explain both the maintenance of mutual aid and how co-operation comes into being in the first place (Whiteley, 1999). To conclude, we suggest that a key element of social capital is a willingness to trust others. The question to answer now is: how do people achieve such willingness? The remainder of this paper will examine several explanations of the origins of social capital measured as social trust.

\section{The Origins of Social Capital: Theories and Hypotheses}

The theory of what determines social trust as a major component of social capital is sketchy at best (Alesina and La Ferrara, 2000: 3; Glaeser etal., 2000). Although no clear-cut guidance to specific determinants exists, there is at least some understanding in the literature as to its origins. There are at least six approaches concerning how to explain the formation of social trust in the relevant literature.

First of all, following Tocqueville (1994), the main school of thought has proposed that associational membership creates generalized trust (Brehm and Rahn, 1997; Putnam, 1993, 1995a, 1995b, 2000). In a well-known widespread view, this relation is considered the core of social capital theory (Stolle and Rochon, 1999). Ever since the publication of Almond and Verba (1965) we know that associational membership furthers political activity as well as the support of democratic norms. In later research, Verba, Schlozman, and Brady (1995) have observed that citizens who engage in voluntary associations learn self-respect, group identity, and public skills. Scholars of the social capital school add to these findings that such associations also provide a framework in which co-operative attitudes, reciprocity, and trust can be fostered. Particularly, face-to-face interaction among members of associations is seen to promote social trust. Therefore, Putnam (1995b: 666) writes that 'people who join are people who trust', and according to Ostrom (1990: 206) 'networks of civic engagement foster robust norms of reciprocity'. However, the traditional 'Tocqueville model' is challenged by at least three arguments. First, Levi (1996: 48) and Newton (1999a: 172, 1999b: 16) question whether voluntary organizations play a major role and instead attach more importance to school, family, neighbourhood, or the workplace, since the great majority of people devote time to these rather than to associational engagement. Hence, these experiences and institutions are likely to have a greater influence on the origins of trust, reciprocity, and co-operation than the limited and sporadic involvement of most people in voluntary organizations. Secondly, Kriesi and Baglioni (2001), for example, doubt whether the original Tocqueville model fits the type of modern society, where the characteristics of associations have changed. Thus, some models of associations have shifted from active involvement in face-to-face organizations to rather advocacy organizations, whose members never actually meet. To be sure, these new and chequebook-based models of association contribute less to the creation of social capital via faceto-face interaction. Hence, the original model of association loses its importance in the formation of social capital. Moreover, the Tocqueville model is criticized, since it is not able to explain how social capital might emerge from a primeval state of non-co-operation. In this situation, anyone who tries to co-operate in a society lacking social capital would simply be exploited (Whiteley, 1999, 2000).

Hence, posing alternatives to the associational model, some scholars claim that the willingness to trust others is the product of personal experiences with one's health, the family, the school, the 
workplace, the media, or interactions with institutions (Alesina and La Ferrara, 2000; Newton, 1999a; Whiteley, 1999). Altogether, these experiences influence the extent of one's life satisfaction. Against this background, we expect that individuals who are more happy and satisfied with their lives are more likely to trust other people than individuals who are unhappy or dissatisfied. Life satisfaction reflects whether one has a generally positive or negative bearing towards the environment or the world in which one lives. In this vein, Inglehart (1990: 43) suggests that 'life satisfaction, happiness, interpersonal trust . . . all tend to go together in a cultural cluster'. Thus, social capital is more likely to be generated when the individuals of a society are happy and satisfied with their lives.

Another explanation of the creation of social capital proposes that social trust is rooted in individual morality (Fukuyama, 2000: 55-57; Uslaner, 1999). In this respect, the willingness to share collective endeavours as well as a set of individual normative beliefs and moral codes, such as the support of fairness or the disapproval of freeriding, condition the attitudes individuals have towards their fellow citizens. According to Uslaner (1999: 217) 'moral values help to overcome collective action problems because they provide a sense of shared idealism'. Hence, human beings equipped with a certain personal morality acquired in early life are likely to be predisposed to trust other people compared to individuals who lack such an attitudinal trait. In this case, Fukuyama (2000: 17) claims that truth telling and the keeping of obligations promotes social trust. To sum up, a society where people strongly believe in moral principles is expected to have a large stock of social capital.

A fourth hypothesis regarding the sources of social capital stresses the role of identification with wide-ranging communities. That is, communities with which individuals identify, but never actually interact on a face-to-face basis, because they generally are large and geographically dispersed (Fukuyama, 2000; Newton, 1999a). Proponents of this view assume that identification with a much broader world of international society promotes a kind of cosmopolitan culture, resulting in individuals who are more tolerant and less suspicious of difference (Alesina and La Ferrara, 2000: 3). In this regard, identification with such a kind of community will generate a larger 'radius of trust', where generalized co-operation in public life is much higher (Fukuyama, 2000: 17). As a result, we expect that individuals who strongly share a cosmopolitan culture are more likely to further social trust than individuals who are unreasonably and intolerantly devoted to their immediate community.

According to a fifth hypothesis, the ability to trust others is the product of the citizens' confidence in political institutions, i.e. the political trust or the 'trust from above' (Hardin, 1992; Knack and Keefer, 1997: 1279; Fukuyama, 2000: 242; Newton, 1999a; Paxton, 1999; Rothstein, 2000). ${ }^{5}$ According to this top-down perspective, citizens will trust one another despite the temptation to freeload, as long as they perceive that their political and societal institutions guarantee a credible environment where people can be confident that trusting will be rewarded and not exploited. ${ }^{6}$ That is, as long as the institutional setting is perceived as fair, just, and (reasonably) efficient and as long as opportunistic behaviour such as lying, stealing, or cheating will be sanctioned or prosecuted, the likelihood that citizens will overcome social dilemmas will increase. In this vein, we expect that individuals who strongly trust the institutions due to their performance are more inclined to trust other people than individuals who have no confidence in the institutional setting. However, this view is strongly questioned by several authors who conclude that social and political trust are not necessarily related and that the statistical relationship between these two aspects is rather weak (Kaase, 1999: 15; Newton, 1999a: 183; Newton and Norris, 2000: 61-63). ${ }^{7}$

Finally, empirical and theoretical work focuses on personal resources as crucial foundations of social capital (Alesina and La Ferrara, 2000: 3; Putnam, 1995b, 2000). On that score, more education expands the horizon of individuals and makes people more open-minded in order to accept otherness. In this way, education supplies us with knowledge and information that form the basis of daily social interaction (Newton, 1999b: 18). It helps to bridge contacts and provides us with the leap of faith needed for generalized trust. Likewise, income is expected to have an effect on trust, because a rich, secure person does not suffer much when he or she has trusted the wrong person. 
To sum up, according to the so-called Luke theorem, ${ }^{8}$ we present the hypothesis that individuals endowed with a high socio-economic status will be more likely to trust other people and thereby raise its stock of capital with a social investment.

\section{Measurement Issues}

For our analysis, we are going to rely on data from the mid-1990s version of the World Values Survey, which provides a sample of 1212 cases for Switzerland in 1996. The World Values Survey is a multi-nation study that asks identical questions in each country (Inglehart etal., 2000). The survey was carried out through face-to-face interviews, consisting of adult Swiss citizens only. ${ }^{9}$ Our dependent variable is generalized social trust. In line with leading scholars of the social capital school generalized trust is seen as a key component of social capital, because it can act as a social lubricant that enables a variety of forms of social interaction and cooperation (Coleman, 1990; Newton, 1999b; Putnam, 2000; Stolle, 1998; Whiteley, 1999). The crucial question for our purpose is the following: 'Generally speaking, would you say that most people can be trusted or that you can't be too careful in dealing with people?'. We define those individuals as trusting who answer that 'most people can be trusted' and those who say that 'you can't be too careful' as nontrusting. The key variable we want to explain, social trust, is therefore a dummy taking the value ' 1 ' if the respondent is trusting, and ' 0 ' otherwise. ${ }^{10}$ We estimate logistic regressions for the likelihood that the respondent is trusting of others. According to the data from the World Values Surveys in Switzerland, slightly more than 40 per cent of the individuals trust other people (see Table 1). Compared to other industrialized countries, the country under investigation takes a middle position regarding the figures for interpersonal or social trust. In this

Table 1. Social trust in OECD countries, 1981-1997 (\%)

\begin{tabular}{|c|c|c|c|c|}
\hline Country & 1981-1984 & 1990-1993 & 1995-1997 & 1981-1997 \\
\hline Norway & 62 & 65 & 65 & 64 \\
\hline Sweden & 57 & 66 & 60 & 61 \\
\hline Denmark & 53 & 58 & & 56 \\
\hline Finland & 57 & 63 & 49 & 56 \\
\hline Netherlands & 45 & 54 & & 50 \\
\hline Canada & 49 & 47 & & 48 \\
\hline Australia & 48 & & 40 & 44 \\
\hline Ireland & 41 & 47 & & 44 \\
\hline United States & 41 & 49 & 36 & 42 \\
\hline Japan & 42 & 42 & 42 & 42 \\
\hline Switzerland & & 43 & 41 & 42 \\
\hline United Kingdom & 43 & 44 & 30 & 39 \\
\hline Germany & 30 & 38 & 42 & 37 \\
\hline Spain & 35 & 34 & 30 & 33 \\
\hline Belgium & 29 & 34 & & 32 \\
\hline Austria & & 32 & & 32 \\
\hline Italy & 27 & 35 & & 31 \\
\hline France & 25 & 23 & & 24 \\
\hline Portugal & & 22 & & 22 \\
\hline Average & 43 & 43 & 42 & 43 \\
\hline
\end{tabular}

Notes: The question asked is: 'Generally speaking, would you say that most people can be trusted or that you can't be too careful in dealing with people?'

The entries are percentages saying 'most people can be trusted'. 'Don't knows' are excluded.

Source: World Values Survey 1981-1984, 1990-1993, and 1995-1997. 
respect, the Scandinavian countries display particularly high amounts of trust, while Spain, Belgium, Austria, Italy, France, and Portugal are seen to show lower levels.

Among the explanatory variables we include indicators of associational membership, life satisfaction, personal immorality, cosmopolitan culture, institutional confidence, personal resources, and measures capturing the social background. Since social capital theory relies on the thesis that faceto-face contact is a key ingredient for the development of trust, we use active membership rather than inactive membership to measure associational life (Stolle and Rochon, 1999). In addition, for the sake of comparison we distinguish between various forms of associational engagement. In line with the studies of Stolle and Rochon $(1998,1999)$ we categorize political associations (political groups and environmental organizations), economic associations (labour unions and professional organizations), cultural associations (church or religious organizations and art, music, or educational organizations), community associations (welfare and charitable organizations), and private interest associations (sport or recreation organizations). ${ }^{11}$ We also differentiate between these diverse modes of associations, since being active in a voluntary organization differs with respect to its ability to create social trust. According to the argument of the changing modes of organization, we expect no impact of associations in which the vast majority of the non-activists can be characterized as chequebook members. These new models of associations no longer constitute a decisive framework for face-to-face interactions where members learn co-operative attitudes. According to our Swiss survey, this accounts for political associations (political groups and environmental organizations), economic associations (labour unions and professional organizations), and community associations (welfare and charitable organizations), which incorporate less than 10 per cent of active membership in the mid-1990s. Accordingly, we expect cultural associations (church or religious organizations and art, music, or educational organization) and private interest associations (sport or recreation organizations) to influence the creation of social trust. These rather traditional types of organizations include a relatively large number of active members who actually meet in face-to-face interactions in which trust can be promoted. Finally, social capital theory primarily focuses on apolitical associations as the typical sources of social trust (Stolle, 1998).

To measure the extent of life satisfaction we combine three items (degree of happiness, level of satisfaction with financial situation, and satisfaction with life as a whole) into an overall personal satisfaction scale. The indicators of personal immorality are a series of five ten-point scales in which the respondent is asked if various courses of action are justifiable or not. ${ }^{12}$ These respective aspects of morality are combined into a personal morality index extracted from a principal component analysis. The identification with a large and geographically dispersed community, i.e. the cosmopolitan culture is measured in two different ways. First, it is measured by asking the individuals which geographical area they identify with most strongly. ${ }^{13}$ Secondly, by asking the individuals to what extent they are proud to be Swiss. We show that the less patriotic individuals are and the more they identify with geographical areas where face-to-face interaction with the overwhelming majority of their fellow citizens is not possible (e.g. the continent or the world), the more these individuals are prone to a cosmopolitan culture, characterized by a large radius of trust. We combine these two items to a cosmopolitan culture scale, again extracted from a principal component analysis. Institutional confidence is measured by public support for political institutions, understood as those most closely associated with the core functions of the state (including parliament, the civil service, the armed forces, the legal system, the police, the national government, the political parties, and the church) (Newton and Norris, 2000: 54). Again, we combine these different aspects of the institutional setting into a scale, which consists of the factor score of another principal component analysis. To measure personal resources we use the level of education of the respondent. ${ }^{14}$ Finally, we set controls for television viewing and social background by including age, gender, regional or linguistic provenance, ${ }^{15}$ and marital status. These variables are tested in a more exploratory analysis than on clear theoretical grounds. Especially the work done by Putnam (1995b, 2000, 2001) refers to the crucial role of TV in the context of social capital. ${ }^{16}$ Heavy television consumers are sceptical about the 
benevolence and trustworthiness of other people. In addition, heavy television watching generally increases pessimism in human nature. Taking these arguments together, we expect television watching to erode social trust.

\section{Empirical Evidence}

Which determinants explain the creation of social capital measured in terms of social trust in Switzerland the best? We proceed in three steps. The first estimates relate to the six leading determinants of social capital. The second equation comprises the same variables with additional control variables. Finally, the third model contains only the statistically significant determinants of the preceding model. The main results can be listed as follows: at first glance, the estimations of Table 2 seem to confirm four out of the six main hypotheses concerning the origins of social capital. Most effects of the variables have the expected direction and replicate former findings (e.g. Whiteley, 1999). Nevertheless, starting with the variables of the associational life we notice that activist engagement in associations has no impact on social trust in Switzerland. That is, in contrast to the expectation given by the Tocqueville model, no single type of associational activism promotes trust. Although in Model 1, face-to-face interaction among members in cultural associations seems to make a difference, this result is not maintained if we control for other variables (Model 2) ${ }^{17}$ In this respect, Switzerland is in line with Germany, where Whiteley (1999: 41) also found no statistically significant correlation between voluntary activity and social trust. Additionally, moral values also have no influence on social trust in Switzerland.

Despite these findings, the models exhibit other statistically significant determinants among personal resources, psychological variables, and individual attitudes. According to Model 3, the strongest effect relates to the influence of institutional confidence. In other words, strong confidence in political institutions enhances the likelihood of interpersonal trust. Here, the odds ratio of 1.56 means that the odds for trusting other people are $0.61 \times 1.56=0.95 .^{18}$ The odds ratio indicates the factor by which the odds for trusting are changed due to a one-unit-change in the independent variable. ${ }^{19}$ Moreover, the probability of trusting other people increases by over 50 percentage points to 0.88 compared to the same situation without further information $(p=0.38)$, when we change the institutional confidence index from the lowest score (respondent has no confidence in the political institutions at all) to the highest score possible (respondent has a great deal of confidence in the political institutions). Another strong effect is associated with education. In this case, a one-unit increase in education (from the lowest possible level to the highest one) increases the probability of trust by 25 percentage points. Moreover, Table 2 highlights that respondents who are satisfied with their lives in Switzerland are more trusting than respondents who are dissatisfied with life. Thus, a change in the index of life satisfaction from the lowest score (respondent is completely dissatisfied with his life) to the highest value (respondent is absolutely satisfied with his life) enhances the likelihood of trusting other people by 25 percentage points. With regard to the cosmopolitan culture index, the results suggest that Swiss respondents with a more cosmopolitan attitude are more likely to trust others than respondents who unreasonably identify with the immediate community of their well-known town or region. The probability of trust increases by 15 percentage points compared to the situation without further information, when we change the cosmopolitan culture index from the lowest score (respondent strongly identifies with his immediate community) to the highest score possible (respondent shares a cosmopolitan attitude).

Finally, among the control variables the strongest effect is the one of daily television consumption. The more the Swiss respondents watch TV, the less likely they are to trust other people. A one-unit increase in the variable daily television viewing (from not watching TV to watching more than three hours a day) decreases the probability of trusting other people by 24 percentage points compared to the situation without further information. Furthermore, it was found that regional provenance matters. Respondents who live in the German speaking part of Switzerland are more trusting other people than the respondents from the French speaking region or Ticino. While for respondents from the German part of Switzerland 
Table 2. Social capital regression models for Switzerland, $1995 / 96$

\begin{tabular}{|c|c|c|c|}
\hline Independent variables & Model 1 & Model 2 & Model 3 \\
\hline Intercept & $-0.96 * * *$ & $-1.32 * *$ & $-1.05^{*}$ \\
\hline Political association activism & $\begin{array}{c}0.07 \\
(1.46) \\
1.07\end{array}$ & $\begin{array}{c}0.08 \\
(1.50) \\
1.08\end{array}$ & \\
\hline Economic association activism & $\begin{array}{c}-0.03 \\
(-0.61) \\
0.97\end{array}$ & $\begin{array}{c}-0.03 \\
(-0.50) \\
0.98\end{array}$ & \\
\hline Cultural association activism & $\begin{array}{c}0.09 \\
(1.74)^{*} \\
1.01 \\
\ldots \ldots\end{array}$ & $\begin{array}{c}0.06 \\
(1.00) \\
1.06 \\
\ldots \ldots \ldots\end{array}$ & \\
\hline Community association activism & $\begin{array}{r}-0.17 \\
(-0.61) \\
0.84\end{array}$ & $\begin{array}{c}-0.24 \\
(-0.83) \\
0.79\end{array}$ & \\
\hline Private interest association activism & $\begin{array}{c}0.15 \\
(1.09) \\
1.16\end{array}$ & $\begin{array}{c}0.17 \\
(1.13) \\
1.18\end{array}$ & \\
\hline Life satisfaction & $\begin{array}{l}0.15 \\
(2.21)^{* *} \\
1.16\end{array}$ & $\begin{array}{l}0.13 \\
(1.81)^{*} \\
1.14\end{array}$ & $\begin{array}{l}0.16 \\
(2.40)^{* *} \\
1.18\end{array}$ \\
\hline Personal immorality & $\begin{array}{c}-0.10 \\
(-1.51) \\
0.91\end{array}$ & $\begin{array}{r}-0.01 \\
(-0.11) \\
0.99\end{array}$ & \\
\hline Cosmopolitan culture & $\begin{array}{l}0.23 \\
(3.21)^{* * *} \\
1.26\end{array}$ & $\begin{array}{l}0.18 \\
(2.24) * * \\
1.19\end{array}$ & $\begin{array}{l}0.16 \\
(2.19)^{* *} \\
1.18\end{array}$ \\
\hline Education & $\begin{array}{l}0.99 \\
(2.96)^{* * *} \\
1.26\end{array}$ & $\begin{array}{l}1.03 \\
(2.89) * * * \\
2.80\end{array}$ & $\begin{array}{l}1.10 \\
(3.24) * * * \\
2.84\end{array}$ \\
\hline Institutional confidence & $\begin{array}{l}0.43 \\
(5.64)^{* * *} \\
1.55\end{array}$ & $\begin{array}{l}0.45 \\
(5.79)^{*} * * \\
1.57\end{array}$ & $\begin{array}{c}0.45 \\
(6.02) * * * \\
1.56\end{array}$ \\
\hline Daily television viewing & & $\begin{array}{l}-1.40 \\
(-3.97)^{* * *} \\
0.25\end{array}$ & $\begin{array}{c}-1.33 \\
(-3.96)^{* * *} \\
0.27\end{array}$ \\
\hline Gender & & $\begin{array}{l}0.30 \\
(2.02)^{* *} \\
1.35\end{array}$ & $\begin{array}{l}0.26 \\
(1.84)^{*} \\
1.30\end{array}$ \\
\hline Age & & $\begin{array}{c}0.01 \\
(1.40) \\
1.00\end{array}$ & \\
\hline
\end{tabular}


Table 2. continued

\begin{tabular}{|c|c|c|c|}
\hline Marital Status & & $\begin{array}{c}-0.04 \\
(0.28) \\
0.96\end{array}$ & \\
\hline Regional provenance & & $\begin{array}{l}0.63 \\
(3.72)^{* * *} \\
1.87\end{array}$ & $\begin{array}{l}0.69 \\
(4.21) * * * \\
1.99\end{array}$ \\
\hline Pseudo $\mathrm{R}^{2}$ & 0.11 & 0.16 & 0.16 \\
\hline Chi-square & $81.73 * * *$ & $123.22 * * *$ & $120.76^{* * *}$ \\
\hline Number of observations & 810 & 804 & 846 \\
\hline
\end{tabular}

the probability of trust increases by 17 percentage points, living in a French- or Italian-speaking canton diminishes the likelihood of trusting by the same amount. Furthermore, the results indicate that gender matters. Women are more likely to trust others than men. While for women the probability of trust increases by 6 percentage points, being a man reduces the likelihood of trusting by the same number. However, age and marital status do not seem to make a difference regarding social trust in Switzerland.

With regard to the predicted probabilities given a set of values in the explanatory variables we gain the following results: Based on the logit model, 95 per cent of the respondents are predicted to trust other people, if they are female, if they have a lot of confidence in their institutions, if they share a strong cosmopolitan attitude, if they are very satisfied with their life, if they obtain the highest level of education possible, if they live in the Germanspeaking region of Switzerland, and if they watch no television at all. ${ }^{20}$ By contrast, only 1 per cent of Swiss citizens are predicted to trust if they are male, if they are unreasonably and intolerantly devoted to the immediate community of their well-known town or region, if they have no confidence in their political institutional setting and no education at all, if they are very dissatisfied with their life, and if they are heavy television consumers (i.e. more than 3 hours a day) who live in the French or Italian speaking part of the country.

\section{Conclusion}

The notion of social capital has attracted great academic and journalistic attention. In this paper we have scrutinized the foundations of social capital measured in terms of social trust in Switzerland. Our primary findings can be summarized in three points. First, while the core of social capital theory is that social trust is built upon face-to-face interactions in voluntary organizations, the analysis indicates that the Tocqueville model does not apply to Swiss society. In Switzerland, associational life plays no particular role in creating social trust. How can this finding be explained? First, notwithstanding the obvious result, we have to be conscious of the limits of the analysed data. The Swiss World Values Survey provides no detailed information about the respondents' involvement in associations beyond the question of active or passive membership. Hence, we do not know whether trust increases with the length of time spent in associations, or whether it is a function of the level of engagement. Secondly, in contrast to the lack of a direct impact of associational activism on social trust, it might be that associational membership 
contributes to life satisfaction and institutional confidence and that, therefore, it indirectly contributes to social trust as well. Although one needs to examine more profoundly how these different determinants relate to each other sequentially, further estimations reveal that only cultural associational activism promotes institutional confidence, and only active membership in sport organizations fosters life satisfaction. Thirdly, one could argue that merely private or personalized trust results from co-operative experiences with the immediate circle of known people or with fellow members of a voluntary association, and is also directed toward them (Stolle, 1998: 503). In this regard, however, generalized trust extends beyond the boundaries of face-to-face interaction and is more likely to emerge in response to experiences and institutions outside the activist membership in associations (Levi, 1996; Newton, 1999b).

Secondly, this study has indeed pointed to some important sources of generalized trust creation outside of associations, which appear to be rather strong in terms of empirical evidence. Specifically, the foundations of social trust in Switzerland embrace personal resources, individual attitudes, psychological determinants, and social background variables. In this vein, it should be noted that Swiss citizens who are generally satisfied with their lives are more likely to trust others. Switzerland is in this regard by no means an exceptional case. Life satisfaction is also quite strongly associated with social trust in the USA, France, Great Britain, Italy, and Germany. Furthermore, while moral values do not affect the likelihood of trusting, social trust is contingent upon confidence in political and societal institutions, education, daily television consumption, and cosmopolitan culture. The more Swiss citizens have confidence in their institutional setting, the better they are educated, the more they share a cosmopolitan attitude, and the less they watch television, the more likely they are to trust other people. Finally, gender and regional provenance do matter in Switzerland. In Switzerland, men are less trusting than women and people from the German part of Switzerland are more likely to trust than their fellow citizens from the French or Italian speaking regions of the country.

Among these decisive determinants, the strongest effect relates to the influence of institutional confidence. The particular relationship between political and social trust can best be explained if one takes into account three striking idiosyncrasies of the Swiss political system. First, political culture in Switzerland is to a large extent influenced by its direct democracy. On one hand, this institution provides citizens with opportunities for more indepth deliberation and communication, out of which norms of reciprocity and trust can emerge. On the other hand, direct legislation offers opportunities of participation to the Swiss citizens in the decision-making process, which in turn enhance confidence in political institutions and policy formulation. Secondly, at each level of the Swiss administration, public tasks are fulfilled by civil servants and by the self-administration (Milizverwaltung) of ordinary, mostly unpaid people, who have been nominated to perform a specific task for the commune or the canton. ${ }^{21}$ Again, this institution works as a transmission mechanism between political and social trust. As active members of the community, the Swiss are likely to trust the political authorities and their key actors, i.e. their fellow citizens. Finally, emphasis should also given to the importance of a general principle which pervades the Swiss political system - the principle of subsidiarity (Kriesi and Baglioni, 2001). According to this principle, political authorities only intervene when the civil society or economy are no longer capable of solving a problem (Kriesi, 1998: 264). The consequences of this principle are twofold. First, at the moment of state intervention, any policy to be adopted is pre-structured by already established private solutions. Secondly, this elaborate interpenetration of the political authorities and private agencies encourages both trust in political institutions and social trust.

Considering the challenges to governance, the available findings offer at least two ways for public policy to sustain or even to create social capital in Switzerland. The first way concentrates on educational policy, since social capital takes root in education. In this respect, governments should consider that curbing educational programmes not only diminishes human capital, but also lessens the stock of social capital. In particular, this holds true for university and college education. As Newton (1999b: 19) points out, 'in these last few years of education, people learn most about how to relate 
not only on those who are known personally, but also to those who one may never meet . . In this way, education may help to create social solidarity for a community'. To be sure, educational policy cannot be the sole source of social capital. However, it does constitute an important part of the story. The second way refers to the impact of political institutions. Against the background of the particular influence of the institutional setting on social capital, governments are well advised to maintain confidence in political institutions. In this case, it should be added that it is probably rather the decision-maker within the institutional setting than the formal institution as such that people evaluate (Rothstein, 2000). In this vein, governmental performance and the conduct of decision-makers in office influence the public evaluation of formal political institutions. A great deal of confidence in the institutional setting provides an important breeding ground for social trust.

\section{Notes}

1. Some of the information for this article was generously provided by Andreas Diekmann, Axel Franzen, Adrian Vatter, and most notably Fritz Sager. I would like to thank them and also the two anonymous referees for their thoughtful comments on the project.

2. Social Capital in its contemporary guise was first identified as such by Hanifan (1916); Jacobs (1961); Loury (1977). For an overview see Haug (1997), Putnam (2000) or Woolcock (1998).

3. Exceptions are the contributions from Freitag (2000, 2001); Joye and Renschler (1996); Joye and Laurent (1997) and Kriesi and Baglioni (2001).

4. Following Gambetta, trust is 'a particular level of the subjective probability with which an agent assesses that another agent or group will perform a particular action, both before he can monitor such action ... and in a context in which it affects his own action' (cited by Kaase (1999: 2-3))

5. Although much writing tends to assume that social and political trust are different sides of the same coin, they are logically different (Putnam, 1995b, 2000: 137). While the former is built on personal knowledge, political trust is built on second-hand sources, for example the mass media. In this regard, interpersonal trust belongs to the private sphere, whereas confidence in political institutions belongs to the public sphere (Newton, 1999a: 179).
6. According to Hardin (1992: 161) 'trust is underwritten by a strong government to enforce contracts and to punish theft. Without such a government, cooperation would be nearly impossible and trust would be irrational'.

7. In this respect, these scholars also challenge the bottom-up relationship between political and social trust. According to that view, a strong and trustworthy civil society creates or strongly reinforces political trust.

8. 'I tell you, that to every one who has will more be given; but from him who has not, even what he has will be taken away' (Luke, 19, 26 NT)

9. For details on the measures, the questions, and the coding of the variables see Table A1 in the Appendix.

10. The measure of social trust remains limited for several reasons. It gives respondents only the option of a simple dichotomy, whereas today most modern survey items present more subtle continuous scales. No social context is presented to the respondents, nor can they distinguish between different categories, such as relative levels of trust in friends, colleagues, family, strangers, or compatriots. It might be very well that the operationalization of social capital is not optimal. Nonetheless, this indicator is selected for several reasons. First, this item has become widely accepted as a standard indicator of the concept following its use as a long timeseries in the American General Social Survey since the early 1970s (see Norris, 2001). Secondly, this indicator is chosen because of the limited availability of other measurement categories in the World Values Survey. Thirdly, social trust as opposed to the associational network dimension is strongly related to socio-economic development and to institutional indicators of democratic development (Norris, 2001).

11. The results of the models were generally unchanged when we experimented with several alternative measurements of associational activism (e.g. membership in cultural, sporting, or recreation associations versus membership in all other organizations; number of active membership in each association).

12. The series comprise 'Claiming government benefits to which you are not entitled'; 'Avoiding paying the fare on public transport'; 'Cheating taxes if you have a chance'; 'Buying something you knew was stolen'; 'Someone accepting a bribe in the course of their duties'.

13. The list contained their town, their region, their nation, their continent, and the world as a whole. 
14. Since there are too many missing values, we decided not to include the respective income of the respondent in the models. Nonetheless, the inclusion of this variable does not change the reported results substantially. Income itself is also strongly related to social trust and points in the expected direction. Moreover, the statistical relationship between education and income is strong $(0.36$, the coefficient is significant at the $1 \%$ level). Thus, against this background, education can be used as a proxy for the socio-economic status of the respondent.

15. German is the language of approximately $64 \%$ of the population. French as major language is spoken in six Swiss cantons (Fribourg, Genève, Neuchâtel, Vaud, Valais, and Jura). They comprise about $19 \%$ of the population. Ticino as the only predominantly Italian speaking canton embraces nearly $8 \%$ of the population. Other languages are spoken by $9 \%$ of the population.

16. Primarily, television does reduce civic engagement, because it competes for scarce time, and it has psychological effects that inhibit social participation. Moreover, specific programmatic content on television (e.g. watching entertainment) undermines civic motivations (Putnam, 2000: 237). Further analyses for the Swiss case reveal significant negative effects of TV watching only on the engagement in economic and cultural associations.

17. According to Freitag (2001) citizens of Germanspeaking cantons participate more intensively in associations and show higher levels of social trust. In this regard, the assumption is very plausible that the effect of our control variable of regional provenance on social trust may be an indirect one, passing through associational activism, rather than a direct one. However, further comparisons between respondents of the German-speaking cantons and of the French- or Italian-speaking part of the country do not corroborate this hypothesis.

18. With respect to Model 3 in Table 2, 319 respondents out of the sample of 846 claim that they are trusting of others. In this case, the odds for trusting are, without further information, 0.61 (319/527), while the probability of trust amounts to $0.38(319 / 846)$.

19. The odds are defined as $O_{i}=P_{i} /\left(1-P_{i}\right)$, in which $P_{i}$ denotes the probability of the occurrence of the event. The probability can be retrieved from the odds as $P_{i}=O_{i} /\left(1+O_{i}\right)$. The odds ratios $O R_{i}$ are defined as $\operatorname{es} p\left(\beta_{\mathrm{i}}\right)$, and $O_{i} \times O R_{i}$ indicates the change in the odds induced by a one-unit change in the independent variable. The impact of an $n$-unit change in the independent variable on the odds is given by $O_{i} \times \mathrm{OR}_{i}{ }^{n}$.
20. The predicted probabilities are based on:

$$
P_{i}=\frac{{ }_{e_{k}{ }_{k} \beta_{k} x_{i k}}}{1+{ }_{e} \beta_{k} \beta_{k i k}}=\frac{1}{1+{ }_{e_{k}}^{\Sigma} \beta_{k} x_{i k}}
$$

21. The main field of Milizverwaltung is local government, but it is found at the cantonal and federal levels as well. Many cantonal and district courts work on the basis of Milizverwaltung, and all members of all parliaments exercise the mandate on a part-time basis (Linder, 1994: 54).

\section{References}

Alesina, A. and La Ferrara, E. (2000) Who Trust Others? Harvard University/Università Bocconi and IGIER, unpublished paper.

Almond, G. and Verba, S. (1965) The Civic Culture: Political Attitudes and Democracy in Five Nations. Little Brown, Boston.

Bourdieu, P. (1983) Ökonoisches Kapital, kulturelles Kapital, soziales Kapital. In Kreckel, R. (ed.) Soziale Ungleichheiten. Göttingen, Verlag Otto Schwartz and Co. Soziale Welt Sonderband 2, pp. 183-198.

Brehm, J. and Rahn, W. (1997) Individual-level evidence for the causes and consequences of social capital. A merican Journal of Political Science, 41, 999-1023.

Coleman, J.S. (1988) Social capital in the creation of human capital. A merican Journal of Sociology, 94 (supp.), S95-S120.

Coleman, J.S. (1990) Foundations of Social Theory. Belknap Press, Cambridge, Mass.

Cusack, T.R. (1999) Social Capital, institutional structures, and democratic performance: a comparative study of German local governments. European Journal of Political Research, 35, 1-34.

Diekmann, A. (1993) Sozialkapital und das Kooperationsverhalten in sozialen Dilemmata. Analyse und Kritik, $15,22-35$.

Freitag, M. (2000) Soziales Kapital und Arbeitslosigkeit: eine empirische Analyse zu den Schweizer Kantonen. Zeitschrift für Soziologie, 29, 186-201.

Freitag, M. (2001) Das soziale Kapital der Schweiz: vergleichende Einschätzungen zu Aspekten des Vertrauens und der sozialen Einbindung. Schweizerische Zeitschrift für Politikwissenschaft, 7, 87-117.

Fukuyama, F. (2000) The Great Disruption: Human Nature and the Reconstitution of Social Order. The Free Press, New York.

Glaeser, E.L., Laibson, D.I., Scheinkman, J.A. and Soutter, C.L. (2000) Measuring trust. Quarterly Journal of Economics, 115, 811-846. 
Gurtman, M.B. (1992) Trust, distrust, and interpersonal problems: a circumplex analysis. Journal of Personality and Social Psychology, 62, 989-1002.

Hanifan, L. J. (1916) The rural school community center. Annals of the American Academy of Political and Social Science, 67, 130-138.

Hardin, R. (1992) The street-level epistemology of trust. Analyse und Kritik, 14, 152-176.

Haug, S. (1997) Soziales Kapital: Ein kritischer Überblick über den aktuellen Forschungsstand. Mannheimer Zentrum für Europäische Sozialforschung, Working Paper, Mannheim.

Inglehart, R. (1990) Cultural Shift in Advanced Industrial Society. Princeton University Press, Princeton, NJ.

Inglehart, R., et al. (2000) World Values Surveys and European Values Surveys 1981-1984, 1990-1993, and 1995-1997. Institute for Social Research, Ann Arbor, Mich.

Jacobs, J. (1961) The Death and Life of Great American Cities. Random House, New York.

Jordana, J. (1999) Collective action theory and the analysis of social capital. In Deth, J. van, Maraffi, M., Newton, K. and Whiteley, P. (eds) Social Capital and European Democracy. Routledge, London, pp. 45-72.

Joye, D. and Laurent, A. (1997) Associative and political participation in Switzerland and France. In Deth, J. van (ed.) Private Groups and Public Life: Social Participation, Voluntary Associations and Political Involvement in Representative Democracies. Routledge, London, pp. 163-182.

Joye, D. and Renschler, I. (1996) Social Capital and Local Living: The Example of 4 Swiss Cities. Unpublished paper, Conference on Social Capital, Milan.

Kaase, M. (1999) Interpersonal trust, political trust and the non-institutionalised political participation in Western Europe. West European Politics, 22, 1-21.

Knack, S. and Keefer, P. (1997) Does social capital have an economic payoff? a cross country investigation. Quarterly Journal of Economics, 112, 1251-1288.

Kriesi, H. (1998) Le systéme politique suisse, 2nd edn. Economica, Paris.

Kriesi, H. and Baglioni, S. (2001) Putting local associations in to their context: preliminary results from a Swiss study of local associations. Paper presented at the General Conference of the European Consortium for Political Research, Canterbury, 6-8 September 2001.

Kunz, V. and Gabriel, O.W. (2000) Soziale Integration und politische Partizipation: Das Konzept des Sozialkapitals - ein brauchbarer Ansatz zur Erklärung politischer Partizipation? In Druwe, U., Kühnel, S.M., and Kunz, V. (eds) Kontext, Akteur und strategische Interaktion. Untersuchungen zur Organisation politischen Handelns in modernen Gesellschaften. Leske und Budrich, Opladen, pp. 47-74.

Levi, M. (1996) Social and unsocial sapital: a review essay of Robert Putnam's Making Democracy Work. Politics \& Society, 24, 45-55.

Linder, W. (1994) Swiss Democracy: Possible Solutions to Conflict in Multicultural Societies. St Martin's Press, New York.

Loury, G. (1977) A dynamic theory of racial income differences. In Wallace, P.A. and LeMund, A. (eds) Women, Minorities, and Employment Discrimination. Lexington Books, Lexington, Mass., pp. 153-188.

Newton, K. (1997) Social capital and democracy. American Behavioural Scientist, 40, 575-586.

Newton, K. (1999a) Social and political trust in established democracies. In Norris, P. (ed.) Critical Citizens: Global Support for Democratic Government. Oxford University Press, Oxford, pp. 169-187.

Newton, K. (1999b) Social capital and European democracy. In Deth, J. van, Maraffi, M., Newton, K., and Whiteley, P. (eds) Social Capital and European Democracy. Routledge, London, pp. 3-24.

Newton, K. and Norris, P. (2000) Confidence in public institutions: faith, culture, or performance? In Pharr, S.J. and Putnam, R.D. (eds) Disaffected Democracies: What's Troubling the Trilateral Countries? Princeton University Press, Princeton, NJ, pp. 52-73.

Norris, P. (2001) Making Democracies Work: Social Capital and Civic Engagement in 47 Societies. Paper presented to the European Science Foundation EURESCO Conference on Social Capital: Interdisciplinary Perspectives, University of Exeter, 15-20 September 2001.

Ostrom, E. (1990) Governing the Commons: The Evolution of Institutions of Collective Action. Cambridge University Press, New York.

Paxton, P. (1999) Is social capital declining in the United States? a multiple indicator assessment. American Journal of Sociology, 105, 88-127.

Putnam, R.D. (1993) Making Democracy Work: Civic Traditions in Modern Italy. Princeton University Press, Princeton, NJ.

Putnam, R.D. (1995a) Bowling alone: America's declining social capital. Journal of Democracy, 6, 65-78.

Putnam, R.D. (1995b) Tuning in, tuning out: the strange disappearence of social capital in America. Political Science and Politics, 28, 664-683.

Putnam, R.D. (2000). Bowling Alone: The Collapse and Revival of American Community. Simon \& Schuster, New York.

Putnam, R.D. (2001) Civic disengagement in contemporary America. Government and Opposition, 36, 135-156. 
Rothstein, B. (2000) Trust, social dilemmas and collective memories. Journal of Theoretical Politics, 12, 477-501.

Rotter, J.B. (1971). Generalized expectancies for interpersonal trust. American Psychologist, 26, 443-452.

Rotter, J.B. (1980) Interpersonal trust, trustworthiness, and gullibility. American Psychologist, 35, 1-7.

Stolle, D. (1998) Bowling together, bowling alone: the development of generalized trust in voluntary associations. Political Psychology, 19, 497-526.

Stolle, D. and Rochon, T.R. (1998) Areall associations alike? member diversity, associational type, and the creation of social capital. American Behavioural Scientist, 42, 47-65.

Stolle, D. and Rochon, T.R. (1999). The myth of American exceptionalism: a three-nation comparison of associational membership and social capital. In Deth, J. van, Maraffi, M., Newton, K., and Whiteley, P. (eds) Social Capital and European Democracy. Routledge, London, pp. 192-209.

Tocqueville, A. de (1994) Über die Demokratie in Amerika. Reclam, Stuttgart.

Torcal, M. and Montero, J.R. (1999) Facets of Social Capital in new democracies: the formation and consequences of social capital in Spain. In Deth, J. van, Maraffi, M., Newton, K., and Whiteley, P. (eds) Social Capital and European Democracy. Routledge, London, pp. 167-191.

Urban, D. (1993). Logit-Analyse: Statistische Verfabren zur Analyse von Modellen mit qualitativen Response-V ariablen. Gustav Fischer Verlag, Stuttgart.

Uslaner, E.M. (1999) Morality plays: social capital and moral behaviour in Anglo-American democracies. In
Deth, J. van, Maraffi, M., Newton, K., and Whiteley, P. (eds) Social Capital and European Democracy. Routledge, London, pp. 213-239.

Verba, S., Schlozman, K. and Brady, H. (1995) Voice and Equality: Civic Voluntarism in American Politics. Harvard University Press, Cambridge.

Whiteley, P. (1999) The Origins of Social Capital. In Deth, J. van, Maraffi, M., Newton, K., and Whiteley, P. (eds) Social Capital and European Democracy. Routledge, London, pp. 25-44.

Whiteley, P. (2000) Economic growth and social capital. Political Studies, 48, 443-466.

Winter, I. (2000) Major themes and debates in the social capital literature: the Australian connection. In Winter, I. (ed.) Social Capital and Public Policy in Australia. Australian Institute of Family Studies, Melbourne, pp. 17-42.

Woolcock, M. (1998) Social capital and economic development: towards a theoretical synthesis and policy framework. Theory and Society, 27, 151-208.

\section{Author's Address}

Markus Freitag, University of Berne, Institute of Political Science, Lerchenweg 36, 3000 Berne 9, Switzerland. Tel.: 00-41-31-631-3738; email: markus.freitag@ipw. unibe.ch

Manuscript received: November 2001. 


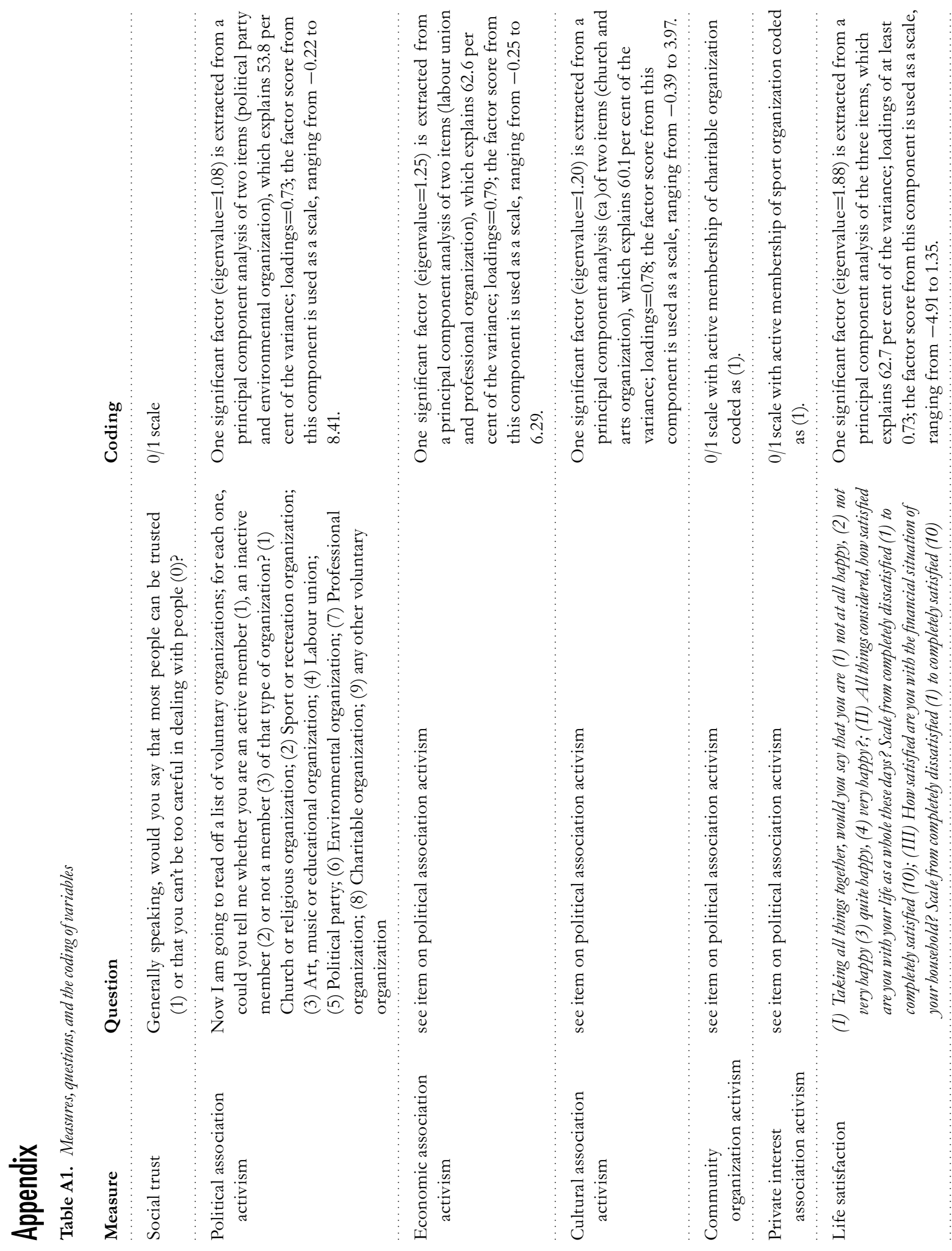




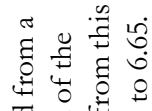

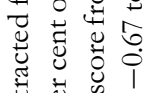

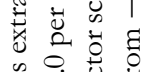

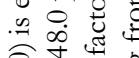

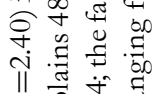

尊蒙

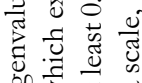

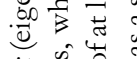

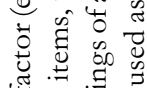

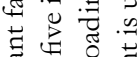

氙苛过

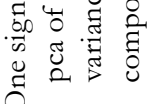

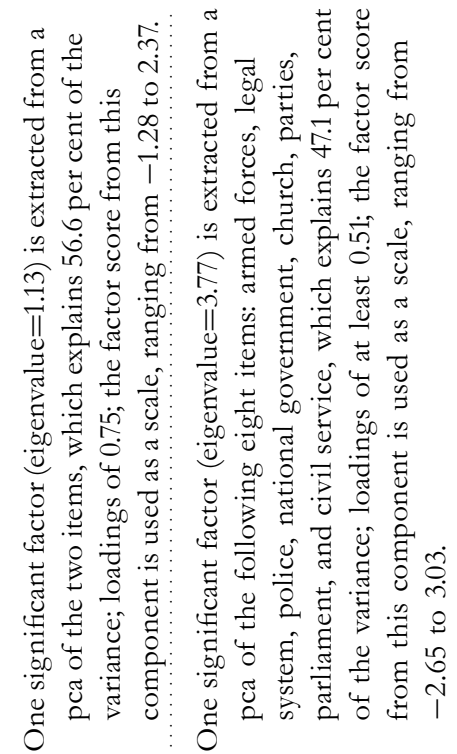

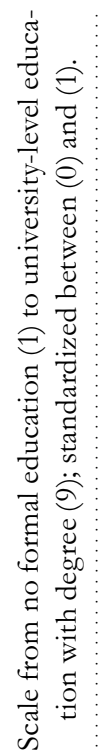

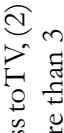

苍苛

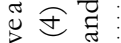

突 仓ิ

苛

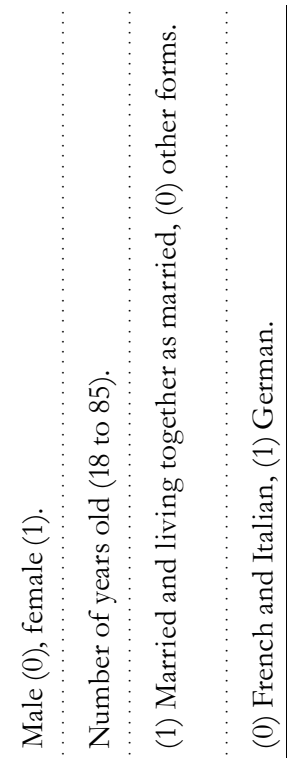

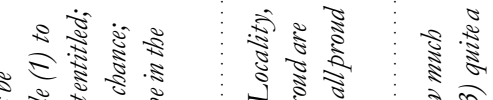

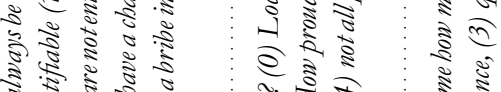

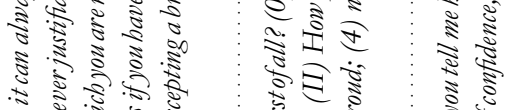

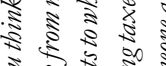

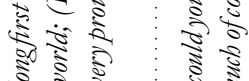

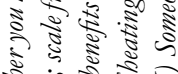

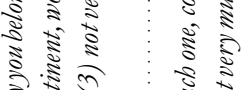

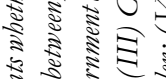

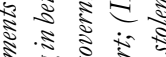

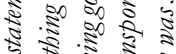

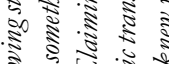

吾

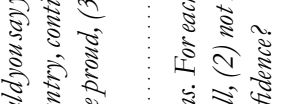

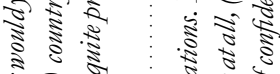

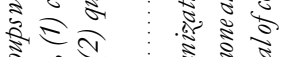

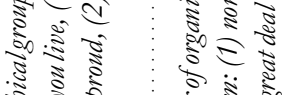

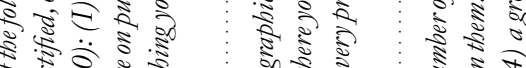

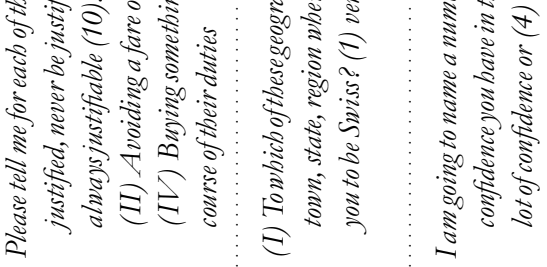

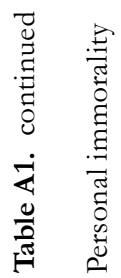

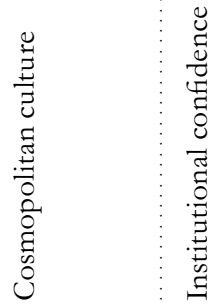
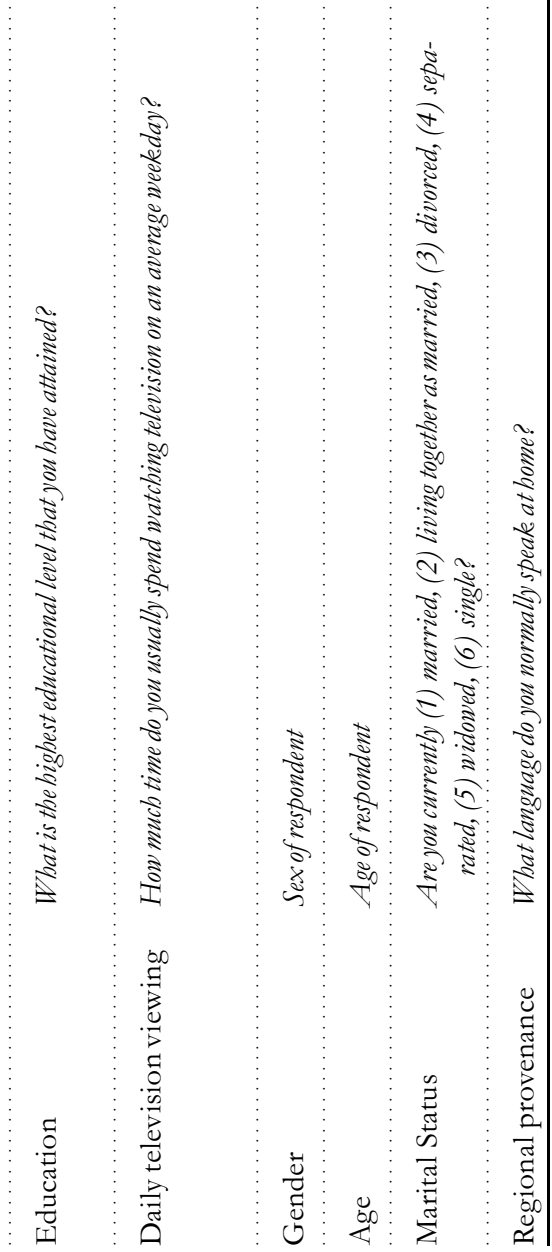